\title{
Pharmacokinetics and Pharmacodynamics of the Nonvitamin K Antagonist Oral Anticoagulant Edoxaban When Administered Alone or After Switching from Rivaroxaban or Dabigatran Etexilate in Healthy Subjects
}

\author{
Dolly A. Parasrampuria ${ }^{1}$ - Doris Weilert ${ }^{2} \cdot$ Jen-Fue Maa $^{3} \cdot$ Victor Dishy $^{1}$. \\ Jarema Kochan ${ }^{1} \cdot$ Minggao Shi $^{1} \cdot$ Karen S. Brown $^{1}$
}

Published online: 23 November 2015

(C) The Author(s) 2015. This article is published with open access at Springerlink.com

\begin{abstract}
Background and Objectives Edoxaban is an oral, oncedaily direct factor $\mathrm{Xa}$ inhibitor. To support the possibility that patients may choose to switch treatment from another nonvitamin $\mathrm{K}$ antagonist oral anticoagulant to edoxaban, this clinical study was conducted to evaluate the pharmacokinetic and pharmacodynamic effects of edoxaban after switching from rivaroxaban or dabigatran etexilate to edoxaban.

Methods In this open-label, three-period, crossover study, healthy subjects received 3 days of edoxaban $60 \mathrm{mg}$ daily, rivaroxaban $20 \mathrm{mg}$ daily, or dabigatran etexilate $150 \mathrm{mg}$ twice daily, followed by edoxaban $60 \mathrm{mg}$ on day 4 .

Results Day 4 edoxaban pharmacokinetic parameters were similar for all treatments. The peak effect of edoxaban on prothrombin time (PT) after 4 days of edoxaban only was $21.8 \pm 2.46 \mathrm{~s}$; after switching from rivaroxaban to edoxaban, peak effect on PT was similar at $21.8 \pm 2.88 \mathrm{~s}$. After switching from dabigatran etexilate to edoxaban, least squares mean activated partial thromboplastin time (aPTT) at $2 \mathrm{~h}$ after administration was $47.6 \mathrm{vs}$ $35.0 \mathrm{~s}$ for edoxaban alone. The treatment difference was 12.8 s (95\% confidence interval 10.5-15.1; $p<0.0001)$. Post hoc analysis revealed that predose aPTT was elevated on day 3 of dabigatran etexilate administration, and on day 4 , indicating a carryover effect from dabigatran. All treatments were well tolerated and there were no safety
\end{abstract}

Karen S. Brown

kbrown@dsi.com

1 Daiichi Sankyo Pharma Development, 399 Thornall St., Edison, NJ 08837, USA

2 Quintiles, Overland Park, KS, USA

3 Daiichi Sankyo, Inc., Parsippany, NJ, USA concerns upon switching, with no increased risk of bleeding.

Conclusions The study results suggest that switching to edoxaban from either rivaroxaban or dabigatran etexilate at the time of the next dose is well tolerated and maintains coagulation status.

\section{Key Points}

Switching from rivaroxaban or dabigatran etexilate to edoxaban at the next scheduled dosing time produces a similar effect on anticoagulant biomarkers as continuing on these drugs.

In most instances, subjects switching to edoxaban from rivaroxaban or dabigatran etexilate can initiate therapy at the next scheduled dosing time.

\section{Introduction}

Edoxaban, a nonvitamin $\mathrm{K}$ antagonist oral anticoagulant (NOAC), is an oral, once-daily, direct, specific, and reversible inhibitor of activated clotting factor X (FXa) [1, 2]. Edoxaban $60 \mathrm{mg}$ once daily has been approved in the US for the prevention of stroke and systemic embolic events in patients with nonvalvular atrial fibrillation, and for the treatment of venous thromboembolism (VTE) [2]. Other approved NOACs include the FXa inhibitors rivaroxaban [3] and apixaban [4], and the direct thrombin inhibitor dabigatran etexilate [5]. Compared with vitamin 
$\mathrm{K}$ antagonists such as warfarin, NOACs provide simple dosing and freedom from frequent coagulation monitoring, along with broader therapeutic windows.

Edoxaban is rapidly absorbed, reaching peak plasma concentration and peak antithrombotic effect within 1-2 h [6], with an oral bioavailability of approximately $62 \%$ [7] and a terminal elimination half-life of $10-14 \mathrm{~h}[8,9]$. The time course profiles of biomarkers indicative of anticoagulant activity closely parallel edoxaban's plasma concentration-time course profile. These include anti-factor Xa (anti-FXa), prothrombin time (PT), activated partial thromboplastin time (aPTT), and thrombin generation parameters.

To support the possibility that patients may switch treatment from another NOAC to edoxaban, this clinical study was conducted in healthy subjects to evaluate the pharmacokinetic and pharmacodynamic effects of edoxaban after switching from steady-state rivaroxaban or dabigatran etexilate to edoxaban. The principal pharmacodynamic measures were PT and aPTT, which are considered most sensitive for rivaroxaban and dabigatran, respectively, as indicated in their product labels $[3,5]$. For completeness, other biomarkers (including anti-FXa and thrombin generation parameters) were also assessed.

\section{Methods}

\subsection{Study Design}

This was an open-label, randomized, three-period, crossover study at a single center in the US. The study was conducted in compliance with the Declaration of Helsinki and in accordance with Good Clinical Practice guidelines and the International Conference on Harmonisation. All study procedures were approved by the IntegReview Institutional Review Board (Austin, TX, USA), and informed consent was obtained from all individual participants included in the study.

The three treatments were: (1) edoxaban $60 \mathrm{mg}$ (Savaysa ${ }^{\circledR}$; Daiichi Sankyo, Inc.) once daily for 4 days; (2) rivaroxaban $20 \mathrm{mg}$ (Xarelto ${ }^{\circledR}$; Janssen Ortho, LLC) once daily for 3 days and (3) dabigatran etexilate $150 \mathrm{mg}$ (Pradaxa $^{\circledR}$; Boehringer Ingelheim) twice daily for 3 days, with treatments 2 and 3 followed by a single oral dose of edoxaban $60 \mathrm{mg}$ on day 4 . Meal times and contents were standardized during treatment periods. On days of blood sampling for pharmacokinetics, edoxaban was administered in the morning with $240 \mathrm{~mL}$ of water, following an overnight fast of at least $10 \mathrm{~h}$. Rivaroxaban was administered with breakfast, while dabigatran etexilate and edoxaban were administered under fasting conditions on days $1-3$. On day 4 of all treatments, subjects continued to fast for an additional $4 \mathrm{~h}$ after edoxaban administration, with water allowed ad libitum except for $1 \mathrm{~h}$ before and after dosing. All treatments were administered in the morning. Each treatment period lasted 5 days, with a washout period of 7 days between treatment periods (Fig. 1).

Blood samples for the quantification of edoxaban plasma concentrations and for pharmacodynamic and biomarker assessments were collected on day 1 of treatment 1 and on day 4 for all treatments at 0 (predose), 0.5, 1, 1.5, 2, $3,4,6,10,14$, and $24 \mathrm{~h}$ postdose. Additional serial blood samples were collected on day 3 of treatment 2 , and were collected at 0 (predose), 1, 2, 3, 4, 6, 12, and 24 h postdose, and at 0 (predose), 1, 2, 4, 6, and $24 \mathrm{~h}$ postdose for the determination of the pharmacokinetics and pharmacodynamics of rivaroxaban. Similarly, additional serial blood samples were collected on day 3 of treatment 3 for the characterization of the pharmacokinetics of dabigatran at 0 (predose), 1, 1.5, 2, 3, 4, and $12 \mathrm{~h}$ postdose, and at 0 (predose), 1, 2, 4, and $12 \mathrm{~h}$ postdose for characterization of pharmacodynamics assessments.

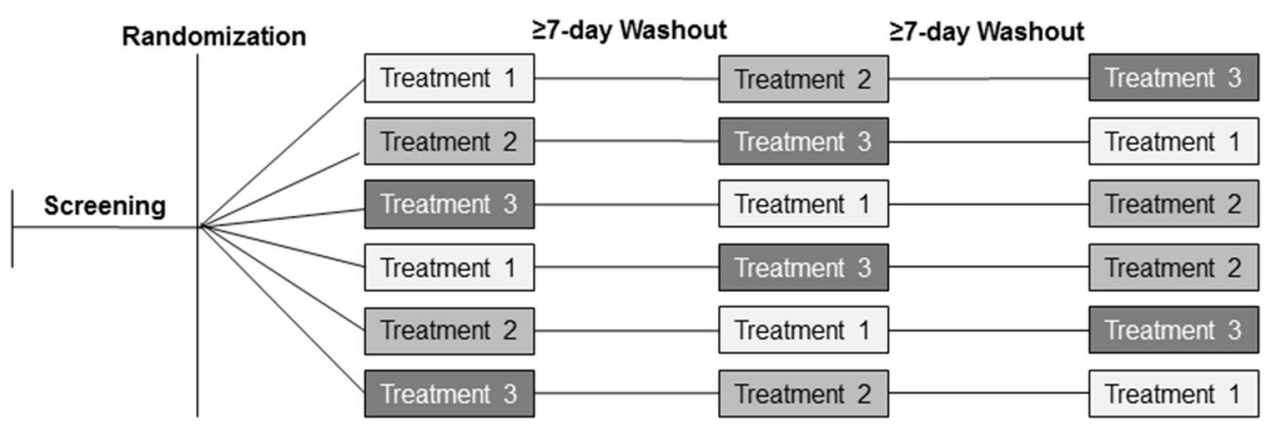

Fig. 1 Study design. Treatment 1: edoxaban $60 \mathrm{mg}$ once daily for 4 days; treatment 2: rivaroxaban $20 \mathrm{mg}$ once daily for 3 days followed by a single oral dose of edoxaban $60 \mathrm{mg}$ on day 4; treatment 3: dabigatran etexilate $150 \mathrm{mg}$ twice daily for 3 days followed by a single oral dose of edoxaban $60 \mathrm{mg}$ on day 4 


\subsection{Study Population}

Subjects were healthy men and women, 18-45 years of age, with a body mass index (BMI) of $18-30 \mathrm{~kg} / \mathrm{m}^{2}$. Subjects had normal coagulation values for PT/international normalized ratio (INR) and aPTT. Exclusion criteria included a history of major bleeding, major trauma, or major surgical procedure of any type within 6 months of the first dose of study medication; a history of minor bleeding within 3 months before the first dose of study medication; a history of peptic ulcer, gastrointestinal bleeding, or bleeding from hemorrhoids; a family history (suspected or documented) of coagulopathy; use of anticoagulants, coagulants, or antiplatelet therapy within 30 days before the first dose of study medication; use of any drugs or substances known to be strong inhibitors or strong inducers of cytochrome P450 (CYP) 3A4/5 enzymes or p-glycoprotein within 28 days before the first dose of study medication; and use of fish oil, acetylsalicylic acid, any over-the-counter medication containing acetylsalicylic acid, nonsteroidal anti-inflammatory drugs, or other supplements (e.g. ginkgo biloba) that could prolong bleeding within 14 days before the first dose of study medication. The use of any of the above mentioned agents during the study was also prohibited. Subjects agreed to abstain from alcohol and specified caffeinated food and drink from 2 days prior to dosing through day 5 of each treatment period, and from food and beverages containing grapefuit or Seville oranges from 10 days before first dosing through the end of the study.

\subsection{Bioanalytical Analysis}

Human plasma samples were analyzed for edoxaban using a liquid chromatographic method with tandem mass spectrometric detection, developed and validated at Advion BioServices (Ithaca, NY, USA). The assay was linear over the range of $0.764-382 \mathrm{ng} / \mathrm{mL}$ for edoxaban. The intraand interassay precision for quality control samples prepared at $0.764,2.29,153$, and $306 \mathrm{ng} / \mathrm{mL}$ were $\leq 11.0$ and $\leq 8.8 \%$, respectively. The intra- and interassay accuracy of these quality control samples were -6.9 to $5.8 \%$ for edoxaban.

Human plasma samples were analyzed by Worldwide Clinical Trials (San Antonio, TX, USA) for free (unconjugated) dabigatran and for rivaroxaban. Quantitations were performed using weighted $1 / x^{2}$ linear least squares (LS) regression analyses generated from calibration standards. For rivaroxaban, the method was validated for a range of $0.500-500 \mathrm{ng} / \mathrm{mL}$, based on the analysis of $0.100 \mathrm{~mL}$ of plasma. The quality control intraday precision and accuracy ranges were $0.7-4.2$ and -3.2 to $6.7 \%$, respectively. The quality control interday precision and accuracy ranges were $1.0-3.1$ and -1.6 to $5.3 \%$, respectively. For dabigatran, the method was validated for a range of $0.500-300 \mathrm{ng} / \mathrm{mL}$, based on the analysis of $0.200 \mathrm{~mL}$ of plasma. The quality control intraday precision and accuracy ranges were $1.1-5.8$ and -12.0 to $-3.0 \%$, respectively. The interday precision and accuracy ranges were $2.7-6.1$ and -7.3 to $-5.0 \%$, respectively.

\subsection{Pharmacokinetic Analyses}

Data from all dosed subjects were analyzed. Plasma concentration-time data for edoxaban were analyzed by noncompartmental methods using Phoenix ${ }^{\text {TM }}$ WinNonlin ${ }^{\circledR}$ version 6.1 (Pharsight Corporation, St. Louis, MO, USA). The following parameters were assessed: maximum plasma concentration $\left(C_{\max }\right)$, time to $C_{\max }\left(T_{\max }\right)$, area under the plasma concentration-time curve during the dosing interval calculated using the linear trapezoidal rule $\left(\mathrm{AUC}_{\tau}\right)$, and the day 4 to day 1 accumulation ratio for $\mathrm{AUC}_{\tau}$. Additionally, trough concentrations $\left(C_{\text {trough }}\right)$ were reported for each treatment.

\subsection{Biomarker Analysis}

Biomarkers were measured using validated methods at Medpace Reference Laboratories (Cincinnati, OH, USA). PT was measured on the Stago PT platform (Parsippany, NJ, USA), using Neoplastin $\mathrm{C} 1+$ as the thromboplastin to measure plasma clotting time. The intraday and interday precision ranges were $0.5-1.8$ and $1.8-2.2 \%$, respectively, and bias ranged from -4.0 to $6.4 \%$.

aPTT was measured in duplicate on the Siemens (Erlangen, Germany) BCS hemostasis analyzer. Calcium was added to trigger the coagulation process and clotting time was measured. The intraday and interday precision ranges were $0.9-1.0$ and $2.4-7.9 \%$, respectively, and bias ranged from -15.6 to $-8.5 \%$.

Anti-FXa was measured using the Biophen heparin 6 assay (Aniara, West Chester, OH, USA). The intraday and interday precision ranges were 3.1-4.9 and 4.8-10.0\%, respectively, and bias reported in two tables within the analytical report ranged from -7.7 to 3.9 and -16.7 to $-4.3 \%$.

The Technothrombin ${ }^{\circledR}$ thrombin generation assay (TGA) (Technoclone, Vienna, Austria) measured fluorescence generated by cleavage of a specific thrombin substrate. The interday precision ranged from 10.4 to $27.1 \%$, while the intraday precision ranges were 7.9-8.3\% for lag time, 3.0-6.0\% for time to peak, 5.2-9.5\% for peak, 14.5-20.2\% for velocity, and 2.5-6.0\% for endogenous thrombin potential (ETP). The bias ranged from -3.8 to $30.9 \%$. 


\subsection{Pharmacodynamic Assessments}

Data from all dosed subjects were analyzed. Biomarker time course profile data were analyzed by noncompartmental methods using Phoenix ${ }^{\mathrm{TM}}$ WinNonlin ${ }^{\circledR}$ version 6.1 (Pharsight Corporation, St. Louis, MO, USA). The following parameters were assessed: minimum observed activity level $\left(A_{\min }\right)$, maximum observed activity level $\left(A_{\max }\right)$, time to maximum observed activity value $\left(T_{\max }\right)$, area under the effect-time curve during dosing interval calculated using the linear trapezoidal rule $\left(\mathrm{AUE}_{\tau}\right)$, change from maximum activity relative to baseline $\left(\Delta A_{\max }\right)$, and percent change in maximum activity relative to baseline $\left(\% \Delta A_{\max }\right)$. The primary endpoint was the 2-h assessment of PT on day 4 when comparing edoxaban with rivaroxaban, and of aPTT on day 4 when comparing edoxaban with dabigatran etexilate. This 2-h timepoint was chosen as it is close to peak effect.

\subsection{Safety Assessment}

Safety assessments included monitoring of incidence and severity of adverse events (AEs); physical examination findings; vital signs; 12-lead electrocardiograms; standard hematology, clinical chemistry, coagulation (PT/INR and aPTT) and urinalysis laboratory tests; and fecal occult blood tests.

\subsection{Statistical Analysis}

The pharmacokinetic and pharmacodynamic parameters were summarized using descriptive statistics for all dosed subjects using SAS version 9.2. Statistical comparison between treatments was performed on day 4 data for the most sensitive biomarker of interest for the anticoagulant that was administered prior to switching to edoxaban. The reference was edoxaban administered alone for a similar duration. The primary endpoint selected for this statistical comparison was the 2-h assessment, as it was close to peak effect. For switching from rivaroxaban, PT measurement at $2 \mathrm{~h}$ was used; while for switching from dabigatran etexilate, aPTT measurement at $2 \mathrm{~h}$ was used. Although the 2-h time point was chosen for primary statistical analyses and sample size, the overall assessment of the effects of treatment switch was made based on the totality of the data and clinical interpretation of the results. Treatment differences were evaluated using an analysis of covariance (ANCOVA) model, fitting the absolute PT or aPTT values as the response variable with baseline (predose on day 1 of treatment 1) PT or aPTT as the covariate and with factors for treatment, treatment sequence, and period fitted as fixed effects. Subject nested within treatment sequence was included as a random effect term. If the $95 \%$ CI for the treatment difference (treatment 2 vs 1) in PT was within the interval $(-1.5,1.5)$, then the PT values were considered equivalent between the two treatments. If the $95 \% \mathrm{CI}$ for the treatment difference (treatment 3 vs 1) in aPTT was within the interval $(-6.5,6.5)$, then the aPTT values were considered equivalent between the two treatments.

\subsection{Sample Size Considerations}

Based on previous trials of edoxaban, a total of 18 healthy subjects was expected to provide $90 \%$ power for the test of equivalence for PT, with an equivalence margin of 1.5 , $\alpha=0.05$, if the difference in means was 0.2 with standard deviation $(\mathrm{SD})=1.2$; and to provide $90 \%$ power for the test of equivalence for aPTT, with an equivalence margin of $6.5, \alpha=0.05$, if the difference in means was 2 with $\mathrm{SD}=4.2$. Therefore, a total of 24 subjects were planned for study enrollment, with no replacement of dropouts.

\section{Results}

\subsection{Subjects}

Twenty-four subjects were randomized to one of six treatment sequences in this three-treatment crossover study. Two subjects did not complete all three treatments. Subjects had a mean age of 31 years, and the majority of subjects were White (58\%) and male (58\%), with an average body weight of $74.1 \pm 12.4 \mathrm{~kg}$ and a BMI of $26.1 \pm 2.7 \mathrm{~kg} / \mathrm{m}^{2}$ (Table 1 ).

Table 1 Subject demographics

\begin{tabular}{ll}
\hline Variable & $N=24$ \\
\hline Age (years; mean \pm SD) & $30.8 \pm 8.1$ \\
Male sex $[n(\%)]$ & $14(58.3)$ \\
Ethnicity $[n(\%)]$ & \\
Hispanic/Latino & $13(54.2)$ \\
Non-Hispanic/Latino & $11(45.8)$ \\
Race $[n(\%)]$ & \\
American Indian/Alaskan native & $4(16.7)$ \\
Black or African American & $5(20.8)$ \\
Native Hawaiian or Pacific Islander & $0(0.0)$ \\
Asian & $0(0.0)$ \\
White & $14(58.3)$ \\
Other & $1(4.2)$ \\
Height $(\mathrm{cm} ;$ mean \pm SD) & $168.1 \pm 8.9$ \\
Weight $(\mathrm{kg} ;$ mean $\pm \mathrm{SD})$ & $74.1 \pm 12.4$ \\
BMI $\left(\mathrm{kg} / \mathrm{m}^{2} ;\right.$ mean $\left.\pm \mathrm{SD}\right)$ & $26.1 \pm 2.7$ \\
\hline
\end{tabular}

$B M I$ body mass index, $S D$ standard deviation 


\subsection{Pharmacokinetics}

When administered once daily, the mean edoxaban plasma concentration-time profile after a single dose on day 1 was similar to that on day 4 (Fig. 2), with minimal accumulation upon multiple dosing. Edoxaban $C_{\text {trough }}$ were similar on days $4(15.4 \pm 6.19 \mathrm{ng} / \mathrm{mL})$ and $5(15.5 \pm 3.98 \mathrm{ng} /$ $\mathrm{mL}$ ), indicating that steady state was achieved by day 4 of once-daily edoxaban administration. Pharmacokinetic parameters were similar following single- and multipledose administration of edoxaban (Table 2) due to the minimal accumulation.

Upon switching from rivaroxaban to edoxaban, or from dabigatran etexilate to edoxaban, the concentration-time profile of edoxaban was similar to edoxaban when administered alone. Pharmacokinetic parameters were also similar following treatment with edoxaban alone or upon switching from rivaroxaban or dabigatran etexilate to edoxaban (Table 2). The most relevant comparison for pharmacokinetics after switching is day 1 administration of

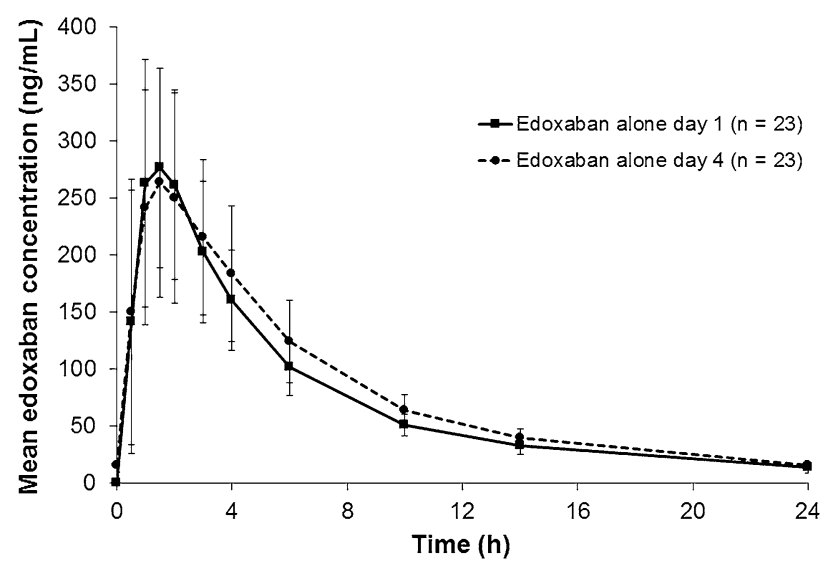

Fig. 2 Mean edoxaban plasma concentration for $24 \mathrm{~h}$ after dosing on day 1 or 4 after treatment 1 (edoxaban alone). Error bars represent the standard deviation edoxaban in treatment 1 . As can be seen from the results, the single-dose pharmacokinetic parameters of edoxaban administered alone and after switching were similar.

The mean pharmacokinetic parameters $C_{\max }$ and $\mathrm{AUC}_{\tau} \pm \mathrm{SD}$ on day 3 for rivaroxaban were $408 \pm 97.8 \mathrm{ng} / \mathrm{mL}$ and $3050 \pm 556 \mathrm{ng} \cdot \mathrm{h} / \mathrm{mL}$, and $140 \pm 42.3 \mathrm{ng} / \mathrm{mL}$ and $921 \pm 265 \mathrm{ng} \cdot \mathrm{h} / \mathrm{mL}$ for dabigatran, respectively. These were comparable to published values and demonstrate adequate exposure to these drugs in this study $[10,11]$.

\subsection{Pharmacodynamics}

\subsubsection{Treatment Over 4 Days with Edoxaban Alone}

The time course profiles of PT (Fig. 3a), aPTT (Fig. 4a), and anti-FXa (Fig. 5) paralleled the concentration-time profile of edoxaban, with a rapid increase to peak effect within 1-2 $\mathrm{h}$, followed by a return to baseline by $24 \mathrm{~h}$. Repeat dosing did not cause additive anticoagulatory effects, as assessed by these biomarkers. Of note, there was a linear relationship between PT, aPTT, anti-FXa, and plasma edoxaban concentration (data not shown). Further, thrombin generation parameters were similar upon single and repeat dosing (Table 3). These data indicate that maximum anticoagulatory effects are observed with the first dose of edoxaban, and that the anticoagulatory effects are consistent upon multiple dosing.

\subsubsection{Switching to Edoxaban After 3 Days of Once-Daily Rivaroxaban Dosing}

Upon switching from rivaroxaban to edoxaban, the time course profile of PT was similar to that observed with edoxaban administered alone (Fig. 3b). The peak effect of edoxaban on PT was similar for both treatments: $21.8 \pm 2.88 \mathrm{~s}$ on day 4 of treatment 2 after switching from

Table 2 Pharmacokinetic parameters of edoxaban administered alone or following a switch from rivaroxaban or dabigatran

\begin{tabular}{|c|c|c|c|c|}
\hline Treatment & $\begin{array}{l}\text { Edoxaban } \\
\text { Day } 1 \text { (treatment } \\
\text { 1) }(n=23)\end{array}$ & $\begin{array}{l}\text { Edoxaban } \\
\text { Day } 4 \text { (treatment } \\
\text { 1) }(n=23)\end{array}$ & $\begin{array}{l}\text { Edoxaban after switching } \\
\text { from rivaroxaban } \\
\text { Day } 4 \text { (treatment 2) } \\
\quad(n=24)\end{array}$ & $\begin{array}{l}\text { Edoxaban after switching from } \\
\text { dabigatran etexilate } \\
\text { Day } 4 \text { (treatment 3) }(n=23)\end{array}$ \\
\hline$C_{\max }(\mathrm{ng} / \mathrm{mL})$ & $309 \pm 97.2$ & $303 \pm 87.7$ & $288 \pm 113$ & $280 \pm 124$ \\
\hline$T_{\max }(\mathrm{h})$ & $1.00(1.00,2.00)$ & $1.50(0.50,4.00)$ & $1.00(0.50,2.00)$ & $1.00(0.50,3.00)$ \\
\hline $\mathrm{AUC}_{\tau}(\mathrm{ng} \cdot \mathrm{h} / \mathrm{mL})$ & $1780 \pm 319$ & $1990 \pm 403$ & $1740 \pm 353$ & $1680 \pm 475$ \\
\hline$C_{\text {trough }}(\mathrm{ng} / \mathrm{mL})$ & $14.0 \pm 5.44$ & $15.5 \pm 3.98$ & $13.4 \pm 5.00$ & $12.8 \pm 4.13$ \\
\hline $\begin{array}{l}\text { Accumulation ratio }\left[\mathrm{AUC}_{\tau} \text { (day }\right. \\
\text { 4)/AUC } \tau \text { (day 1)] }\end{array}$ & - & $1.14 \pm 0.25$ & - & - \\
\hline
\end{tabular}

Data are expressed as arithmetic mean \pm standard deviation, except for $T_{\max }$, which is expressed as median (minimum, maximum)

$A U C_{\tau}$ area under the concentration-time curve during the $24 \mathrm{~h}$ dosing interval, $C_{\max }$ maximum plasma concentration, $C_{\text {trough }}$ trough concentration, $T_{\max }$ time to reach maximum plasma concentration 

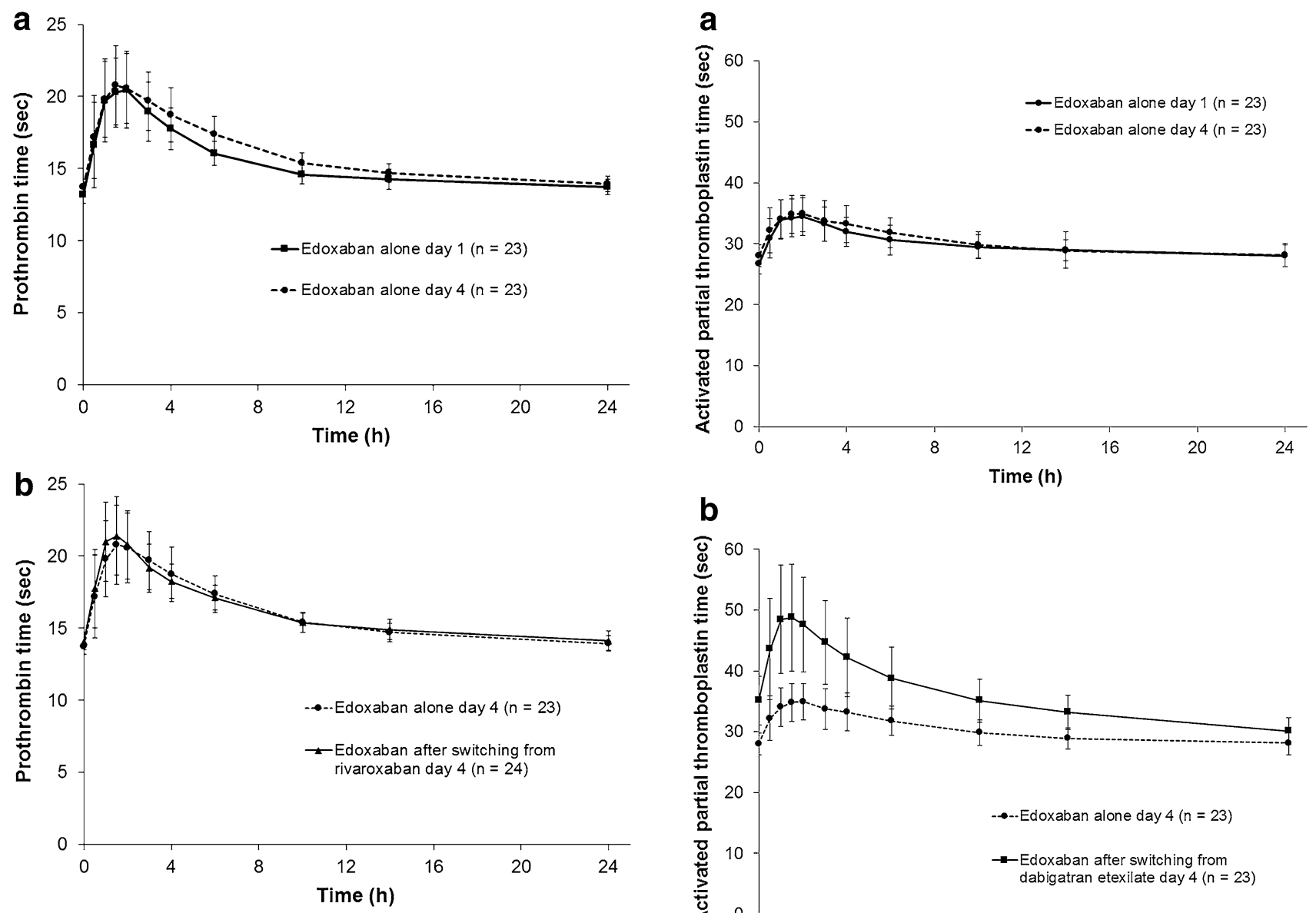

Fig. 3 Mean plasma prothrombin time: a day 1 or 4 after treatment 1 (edoxaban alone); b day 4 after treatment 1 (edoxaban alone) or treatment 2 (edoxaban after switching from rivaroxaban). Error bars represent the standard deviation

rivaroxaban, and $21.8 \pm 2.46 \mathrm{~s}$ on day 4 of treatment 1 , edoxaban alone (Table 3). Other day 4 pharmacodynamic parameters were also similar between the two treatment regimens (Table 3 ).

LS mean PT at $2 \mathrm{~h}$ after dosing (a time point close to $T_{\max }$ ) was $20.8 \mathrm{~s}$ for the regimen of edoxaban after switching from rivaroxaban, and $20.6 \mathrm{~s}$ for edoxaban alone. The treatment difference was $0.25 \mathrm{~s}(95 \%$ confidence interval $[\mathrm{CI}]-1.23$ to $1.73 ; p=0.734$ ). Assessments of aPTT (Table 3), antiFXa (Table 3), and TGA parameters (Table 4) were also similar between the two treatment regimens.

\subsubsection{Switching to Edoxaban After 3 Days of Twice-Daily Dabigatran Etexilate Dosing}

Mean changes in clotting time after treatment with edoxaban on day 4 , as measured by aPTT, were higher after switching from dabigatran etexilate than after treatment with edoxaban alone (Fig. 4b). For treatment regimens of
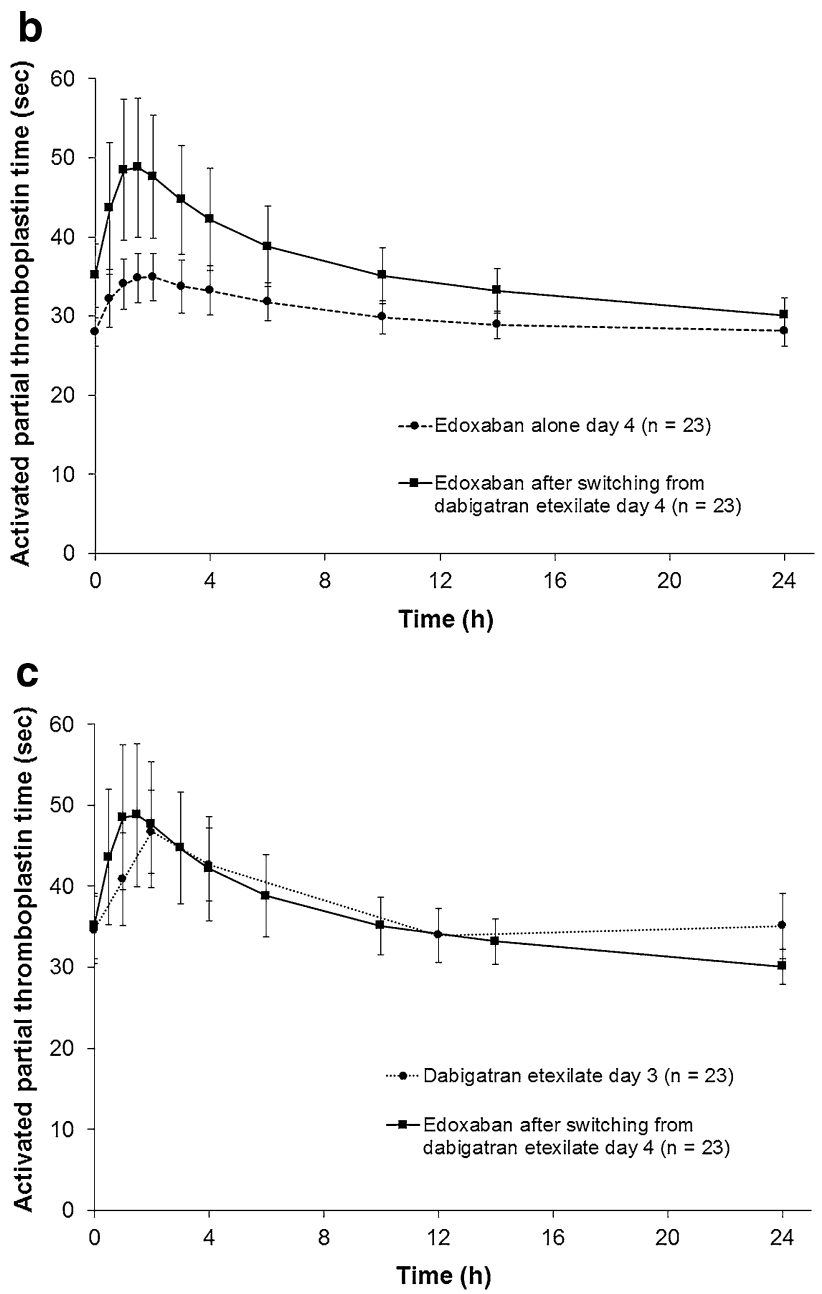

Fig. 4 Mean plasma activated partial thromboplastin time: a day 1 or 4 after treatment 1 (edoxaban alone); $\mathbf{b}$ day 4 after treatment 1 (edoxaban alone) or treatment 3 (edoxaban after switching from dabigatran etexilate); c for treatment 3 , day 3 treatment with dabigatran etexilate or day 4 treatment with edoxaban after switching from dabigatran etexilate. Error bars represent the standard deviation 


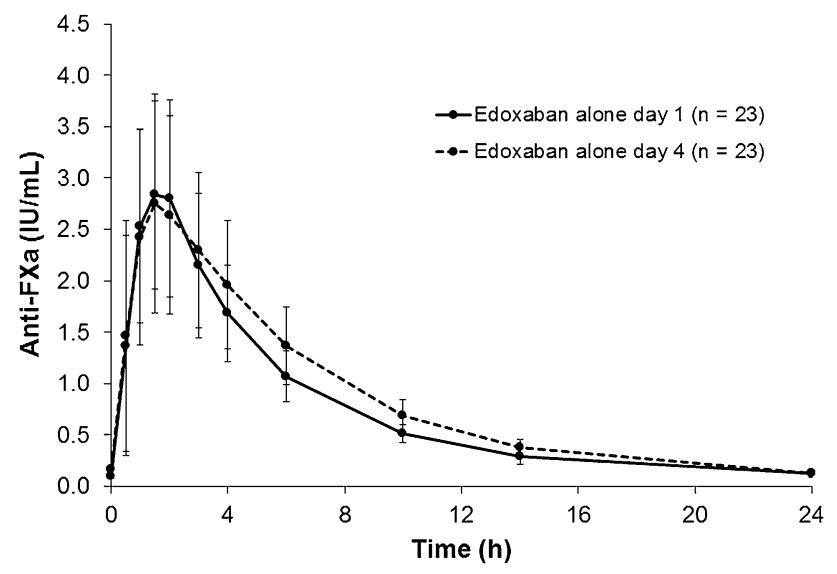

Fig. 5 Mean plasma anti-FXa on day 1 or 4 after treatment 1 (edoxaban alone). Error bars represent the standard deviation

edoxaban after switching from dabigatran etexilate and edoxaban alone, respectively, on day 4 , mean $A_{\max }$ values $\pm \mathrm{SD}$ were $50.8 \pm 8.92$ and $35.9 \pm 3.15 \mathrm{~s}$; median $T_{\max }$ values $(\min , \max )$ were $1.00(0.50,3.00)$ and 1.50 $(0.50,4.00)$ (Table 3).

LS mean aPTT at $2 \mathrm{~h}$ after dosing was $47.6 \mathrm{~s}$ after switching from dabigatran etexilate to edoxaban versus
$35.0 \mathrm{~s}$ for edoxaban alone. The treatment difference was $12.8 \mathrm{~s}$ (95\% CI $10.5-15.1 ; p<0.0001)$. Due to this observation, a post hoc analysis was conducted to assess if this difference was due to lingering effects of dabigatran etexilate twice-daily treatment rather than an edoxaban effect. As shown in Fig. 4b, c (the post hoc comparison for this treatment regimen between day 3 with dabigatran etexilate and day 4 after switching to edoxaban), predose aPTT was elevated on both days 3 and 4, indicating that this was indeed a dabigatran effect (Fig. 4c).

Increased anticoagulation in subjects who switched to edoxaban after treatment with dabigatran etexilate compared with those treated with edoxaban alone was also suggested by three of the TGA parameters. Edoxaban treatment on day 4 after switching from dabigatran etexilate compared with continual edoxaban treatment resulted in ETP $A_{\max }$ values of $3338 \pm 575 \mathrm{mN} \cdot \mathrm{min}$ and $3644 \pm 434 \mathrm{mN} \cdot \mathrm{min}$, lag time $A_{\max }$ values of $55.3 \pm 16.2$ and $37.8 \pm 7.09 \mathrm{~min}$, and time-to-peak $A_{\max }$ values of $74.0 \pm 12.4$ and $58.5 \pm 12.2 \mathrm{~min}$, respectively (Table 4). However, other thrombin generation parameters such as velocity and peak thrombin were similar between the two regimens (Table 3), as were elevations in PT (Table 3) and anti-FXa (Table 3).

Table 3 Pharmacodynamic parameters on day 4

\begin{tabular}{|c|c|c|c|}
\hline Parameter & $\begin{array}{l}\text { Edoxaban alone (treatment } \\
\text { 1) }(n=23)\end{array}$ & $\begin{array}{l}\text { Edoxaban after switching from } \\
\text { rivaroxaban (treatment 2) }(n=24)\end{array}$ & $\begin{array}{l}\text { Edoxaban after switching from } \\
\text { dabigatran etexilate (treatment } 3)(n=23)\end{array}$ \\
\hline \multicolumn{4}{|l|}{ Prothrombin time } \\
\hline$A_{\max }(\mathrm{s})$ & $21.8 \pm 2.46$ & $21.8 \pm 2.88$ & $24.6 \pm 4.25$ \\
\hline$T_{\max }(\mathrm{h})$ & $1.50(0.50,4.00)$ & $1.04(0.50,2.00)$ & $1.00(0.50,3.00)$ \\
\hline $\operatorname{AUE}_{\tau}(\mathrm{s} \cdot h)$ & $382 \pm 16.2$ & $383 \pm 14.7$ & $398 \pm 21.5$ \\
\hline$A_{\min }(\mathrm{s})$ & $13.7 \pm 0.46$ & $13.9 \pm 0.61$ & $14.1 \pm 0.65$ \\
\hline$\Delta A_{\max }(\mathrm{s})$ & $8.58 \pm 2.39$ & $8.72 \pm 2.95$ & $11.7 \pm 4.15$ \\
\hline \multicolumn{4}{|c|}{ Activated partial thromboplastin time } \\
\hline$A_{\max }(\mathrm{s})$ & $35.9 \pm 3.15$ & $36.5 \pm 3.94$ & $50.8 \pm 8.92$ \\
\hline$T_{\max }(\mathrm{h})$ & $1.50(0.50,4.00)$ & $1.00(0.50,4.00)$ & $1.00(0.50,3.00)$ \\
\hline $\operatorname{AUE}_{\tau}(\mathrm{s} \cdot \mathrm{h})$ & $725 \pm 48.8$ & $738 \pm 58.6$ & $863 \pm 87.3$ \\
\hline$A_{\min }(\mathrm{s})$ & $27.7 \pm 1.70$ & $28.4 \pm 2.13$ & $30.0 \pm 2.20$ \\
\hline$\Delta A_{\max }(\mathrm{s})$ & $9.18 \pm 2.11$ & $9.73 \pm 3.54$ & $24.3 \pm 8.35$ \\
\hline \multicolumn{4}{|l|}{ Anti-FXa } \\
\hline$A_{\max }(\mathrm{IU} / \mathrm{mL})$ & $3.14 \pm 0.944$ & $3.23 \pm 1.10$ & $2.83 \pm 1.27$ \\
\hline$T_{\max }(\mathrm{h})$ & $1.50(0.50,4.00)$ & $1.50(0.50,2.00)$ & $1.00(0.50,3.00)$ \\
\hline $\operatorname{AUE}_{\tau}(\mathrm{IU} / \mathrm{mL} \cdot \mathrm{h})$ & $20.7 \pm 4.36$ & $21.9 \pm 5.26$ & $17.3 \pm 5.31$ \\
\hline$A_{\min }(\mathrm{IU} / \mathrm{mL})$ & $0.12 \pm 0.03$ & $0.17 \pm 0.09$ & $0.100 \pm 0.000$ \\
\hline$\Delta A_{\max }(\mathrm{IU} / \mathrm{mL})$ & $3.04 \pm 0.945$ & $3.15 \pm 1.12$ & $2.81 \pm 1.24$ \\
\hline
\end{tabular}

Data are expressed as arithmetic mean \pm standard deviation, except for $T_{\max }$, which is expressed as median (minimum, maximum)

$\Delta A_{\max }$ change in maximum activity relative to baseline, $A_{\max }$ maximum observed activity, $A_{\min }$ minimum observed activity, $A U E_{\tau}$ area under the concentration-time curve during the $24 \mathrm{~h}$ dosing interval, $T_{\max }$ time to reach maximim observed activity 
Table 4 Thrombin generation parameters

\begin{tabular}{|c|c|c|c|c|}
\hline Parameter & $\begin{array}{l}\text { Edoxaban alone } \\
\text { Day } 1 \text { (treatment } 1) \\
\quad(n=23)\end{array}$ & $\begin{array}{l}\text { Edoxaban alone } \\
\text { Day } 4 \text { (treatment } 1) \\
\quad(n=23)\end{array}$ & $\begin{array}{l}\text { Edoxaban after switching from } \\
\text { rivaroxaban } \\
\text { Day } 4 \text { (treatment } 2)(n=24)\end{array}$ & $\begin{array}{l}\text { Edoxaban after switching from } \\
\text { dabigatran etexilate } \\
\text { Day } 4 \text { (treatment } 3)(n=23)\end{array}$ \\
\hline \multicolumn{5}{|c|}{ Endogenous thrombin potential } \\
\hline$A_{\min }(\mathrm{nM} \cdot \min )$ & $1520 \pm 754$ & $1474 \pm 755$ & $1506 \pm 798$ & $1239 \pm 828$ \\
\hline$A_{\max }(\mathrm{nM} \cdot \min )$ & $3635 \pm 432$ & $3644 \pm 434$ & $3680 \pm 462$ & $3338 \pm 575$ \\
\hline$\Delta A_{\max }(\%)$ & $5.54 \pm 5.99$ & $6.21 \pm 11.3$ & $7.49 \pm 14.0$ & $-3.80 \pm 11.4$ \\
\hline \multicolumn{5}{|l|}{ Lag time } \\
\hline$A_{\min }(\min )$ & $15.8 \pm 2.25$ & $16.9 \pm 2.41$ & $15.8 \pm 3.54$ & $20.5 \pm 3.60$ \\
\hline$A_{\max }(\min )$ & $38.3 \pm 8.59$ & $37.8 \pm 7.09$ & $39.9 \pm 9.96$ & $55.3 \pm 16.2$ \\
\hline$\Delta A_{\max }(\%)$ & $130 \pm 46.3$ & $129 \pm 52.6$ & $139 \pm 63.0$ & $238 \pm 100$ \\
\hline \multicolumn{5}{|l|}{ Time to peak } \\
\hline$A_{\min }(\min )$ & $22.2 \pm 4.13$ & $23.7 \pm 4.29$ & $22.0 \pm 5.15$ & $27.5 \pm 7.94$ \\
\hline$A_{\max }(\min )$ & $58.6 \pm 12.6$ & $58.5 \pm 12.2$ & $59.4 \pm 14.6$ & $74.0 \pm 12.4$ \\
\hline$\Delta A_{\max }(\%)$ & $152 \pm 50.7$ & $154 \pm 63.9$ & $155 \pm 72.0$ & $225 \pm 71.8$ \\
\hline \multicolumn{5}{|l|}{ Velocity } \\
\hline$A_{\min }(\mathrm{nM} / \min )$ & $2.62 \pm 1.92$ & $2.40 \pm 1.89$ & $3.04 \pm 2.88$ & $2.13 \pm 1.35$ \\
\hline$A_{\max }(\mathrm{nM} / \min )$ & $61.4 \pm 31.3$ & $58.4 \pm 31.9$ & $67.4 \pm 46.6$ & $46.5 \pm 25.7$ \\
\hline$\Delta A_{\max }(\%)$ & $30.7 \pm 52.2$ & $68.4 \pm 179$ & $78.1 \pm 173$ & $8.84 \pm 70.9$ \\
\hline \multicolumn{5}{|l|}{ Peak thrombin } \\
\hline$A_{\min }(\mathrm{nM})$ & $45.7 \pm 25.5$ & $43.4 \pm 25.1$ & $49.2 \pm 31.9$ & $48.9 \pm 25.2$ \\
\hline$A_{\max }(\mathrm{nM})$ & $323 \pm 98.1$ & $315 \pm 90.6$ & $324 \pm 123$ & $302 \pm 77.0$ \\
\hline$\Delta A_{\max }(\%)$ & $12.4 \pm 21.4$ & $18.7 \pm 56.2$ & $18.2 \pm 58.2$ & $9.28 \pm 39.4$ \\
\hline
\end{tabular}

Data are expressed as arithmetic mean \pm standard deviation

$\% \Delta A_{\max }$ percent change in maximum activity relative to baseline, $A_{\max }$ maximum observed activity value, $A_{\min }$ minimum observed activity value

\subsection{Safety}

Edoxaban, dabigatran etexilate, and rivaroxaban were well tolerated in healthy adult subjects. No subjects withdrew from the study due to treatment-emergent AEs (TEAEs). One subject had mildly elevated creatine kinase levels at a period 2 check-in that were not considered by the investigator to be related to the study drug. The subject was not dosed in period 2; however, the subject was allowed to return for period 3 dosing. The most common ( $\geq 2$ subjects during any treatment) TEAEs were dizziness (one subject in treatment 2 , four subjects in treatment 3), constipation (two subjects in treatment 1 , two subjects in treatment 2), diarrhea (one subject in treatment 1 , two subjects in treatment 3 ), vessel puncture site hemorrhage (two subjects in treatment 3), and nausea (one subject in treatment 3, two subjects in treatment 3 ). Similar proportions of subjects across treatments experienced TEAEs during the study, and all TEAEs were mild or moderate in intensity.

\section{Discussion}

This is the first study to address the effects of switching from other NOACs to edoxaban. Studying pharmacokinetic parameters of edoxaban and pharmacodynamic measures of coagulation after switching from another NOAC can provide clinical guidance for physicians and their patients who may choose to switch from another NOAC to edoxaban. In this study of healthy subjects, steady-state conditions were achieved by 4 days of once-daily edoxaban treatment. We compared 4 days of continual treatment with edoxaban with the immediate effects of switching to edoxaban from previous treatment with rivaroxaban or dabigatran etexilate on day 4. Edoxaban was well tolerated when administered alone or upon switching from dabigatran etexilate or rivaroxaban.

Switching from rivaroxaban to edoxaban on day 4 did not lead to any relevant differences in edoxaban pharmacokinetics or pharmacodynamics compared with 4 days of continual edoxaban treatment. All edoxaban pharmacoki- 
netic parameters examined on day 4 , immediately after switching treatment, were unchanged compared with steady state. The pharmacodynamic marker PT, affected by rivaroxaban in a dose-dependent manner and considered to be sensitive to rivaroxaban [12], also did not differ after switching compared with continual edoxaban treatment $(p=0.734)$. Of note, a sensitive thromboplastin was employed for the measurement of PT to ensure adequate sensitivity to pick up any differences. The $95 \% \mathrm{CI}$ around the difference in LS means $(-1.23,1.73)$ was slightly outside the predetermined criteria for establishing equivalence $(-1.5,1.5)$. However, the LS means were comparable (20.8 s after the switch vs. $20.6 \mathrm{~s}$ for edoxaban alone). The wider-than-expected range of the $95 \% \mathrm{CI}$ is likely due to the small sample size and the relatively unexpected high variability of the raw data. Secondary measures of anticoagulation also showed close similarity between treatment with edoxaban after switching from rivaroxaban compared with treatment with edoxaban alone. In total, the results suggest that switching from rivaroxaban to edoxaban will maintain patients' anticoagulated status.

Switching from dabigatran etexilate to edoxaban on day 4 also did not lead to any relevant differences in edoxaban pharmacokinetics compared with 4 days of treatment with edoxaban alone. A residual effect of dabigatran was observed on the pharmacodynamic marker aPTT, selected for its sensitivity to dabigatran. aPTT was significantly higher after the switch from dabigatran etexilate compared with treatment with edoxaban alone, and the $95 \%$ CI of the treatment difference was outside the range of equivalence. In addition, predose aPTT values were higher on both days 3 and 4 of treatment 3 (edoxaban on day 4 preceded by 3 days of dabigatran etexilate) compared with predose aPTT in those treated with edoxaban alone. This finding is consistent with the reported pharmacology of dabigatran. The aPTT assay is not suitable for precise quantification of anticoagulant effect, and aPTT is less sensitive to edoxaban than to dabigatran, therefore the additive effect of the two anticoagulants cannot be quantified. A carryover anticoagulation effect of dabigatran is supported by changes in the TGA parameters, ETP, lag time, and time to peak. However, not all coagulation markers supported the residual effect of dabigatran. The implication of the residual effect on safety is unknown. Overall assessment of the ability to switch from rivaroxaban or dabigatran etexilate to edoxaban, as specified in the study protocol, is based on the totality of data. In total, the results of this study suggest that switching from dabigatran etexilate to edoxaban will also maintain patients' anticoagulated status. It should be noted that the study has the limitations of having a small number of subjects, being open-label and of short duration, and enrolling only healthy, young subjects.

\section{Conclusions}

Switching from rivaroxaban to edoxaban $24 \mathrm{~h}$ after the last rivaroxaban dose did not affect edoxaban pharmacokinetics and resulted in similar anticoagulant effects in all pharmacodynamic assays compared with multiple administration of edoxaban. Switching from dabigatran etexilate to edoxaban $12 \mathrm{~h}$ after the last dabigatran etexilate dose had no effect on edoxaban pharmacokinetics. Switching from dabigatran etexilate to edoxaban resulted in higher anticoagulant effects of edoxaban for aPTT and select thrombin generation parameters compared with treatment with edoxaban alone, although previous treatment with dabigatran etexilate did not affect other pharmacodynamic markers. Overall, the study results suggest that switching to edoxaban from either rivaroxaban or dabigatran etexilate at the time of the next dose is well tolerated and maintains coagulation status in healthy subjects.

Acknowledgments Editorial support was provided by Terri Schochet, $\mathrm{PhD}$, of AlphaBioCom, LLC, King of Prussia, PA, USA. AlphaBioCom has received funding from Daiichi Sankyo, Inc., Parsippany, NJ, USA.

Author contributions Dolly A. Parasrampuria and Jen-Fue Maa were responsible for the design and performance of the research, analysis of the data, and writing of the manuscript; Karen S. Brown took part in writing the manuscript, designing the research, and analyzing the data; Jarema Kochan designed the research and analyzed the data; Victor Dishy designed and performed the research; Minggao Shi performed the research; and Doris Weilert performed clinical pharmacology and pharmacokinetic oversight.

\section{Compliance with Ethical Standards}

Funding This study was funded by Daiichi Sankyo, Inc.

Conflicts of interest Victor Dishy, Jarema Kochan, Minggao Shi, and Karen S. Brown are employees of and own stock in Daiichi Sankyo Pharma Development. At the time of writing, Dolly A. Parasrampuria and Jen-Fue Maa were employees of and owned stock in Daiichi Sankyo Pharma Development. Doris Weilert is an employee of Quintiles, who were contracted by Daiichi Sankyo, Inc.

Ethics All procedures performed in studies involving human participants were in accordance with the ethical standards of the institutional and/or national research committee and with the 1964 Helsinki declaration and its later amendments or comparable ethical standards.

Informed consent Informed consent was obtained from all individual participants included in this study.

Open Access This article is distributed under the terms of the Creative Commons Attribution-NonCommercial 4.0 International License (http://creativecommons.org/licenses/by-nc/4.0/), which permits any noncommercial use, distribution, and reproduction in any medium, provided you give appropriate credit to the original author(s) and the source, provide a link to the Creative Commons license, and indicate if changes were made. 


\section{References}

1. Furugohri T, Isobe $\mathrm{K}$, Honda $\mathrm{Y}$, Kamisato-Matsumoto $\mathrm{C}$, Sugiyama N, Nagahara T, et al. DU-176b, a potent and orally active factor Xa inhibitor: in vitro and in vivo pharmacological profiles. J Thromb Haemost. 2008;6(9):1542-9.

2. Savaysa ${ }^{\circledR}$ (edoxaban) tablets for oral use. Full prescribing information. Tokyo: Daiichi Sankyo Co., Ltd; 2015. Available at: http://www.accessdata.fda.gov/drugsatfda_docs/label/2015/2063 16lbl.pdf. Accessed 7 Mar 2015.

3. Xarelto ${ }^{\circledR}$ (rivaroxaban) tablets. Full prescribing information. Titusville (NJ): Janssen Pharmaceuticals. 2015. Available at: https://www.xareltohcp.com/shared/product/xarelto/prescribinginformation.pdf. Accessed 7 Mar 2015.

4. Eliquis ${ }^{\circledR}$ (apixaban) tablets for oral use. Full prescribing information. Princeton (NJ), New York (NY): Bristol-Myers Squibb Company, and Pfizer Inc. 2014. Available at: http://www.eliquis. com/eliquis/servlet/servlet.FileDownload?file=00Pi000000GM6I LEA1. Accessed 7 Mar 2015.

5. Pradaxa ${ }^{\circledR}$ (dabigatran etexilate mesylate). Full prescribing information. Ridgefield (CT): Boehringer Ingelheim Pharmaceuticals, Inc. 2014. Available at: http://bidocs.boehringer-ingelheim.com/ BIWebAccess/ViewServlet.ser?docBase $=$ renetnt $\&$ folderPath $=/$ Prescribing\%20Information/PIs/Pradaxa/Pradaxa.pdf. Accessed 7 Mar 2015

6. Ogata K, Mendell-Harary J, Tachibana M, Masumoto H, Oguma T, Kojima M, et al. Clinical safety, tolerability, pharmacokinetics, and pharmacodynamics of the novel factor Xa inhibitor edoxaban in healthy volunteers. J Clin Pharmacol. 2010;50(7):743-53.

7. Matsushima N, Lee F, Sato T, Weiss D, Mendell J. Bioavailability and safety of the factor Xa inhibitor edoxaban and the effects of quinidine in healthy subjects. Clin Pharm Drug Dev. 2013;2:358-66.

8. Mendell J, Zahir H, Matsushima N, Noveck R, Lee F, Chen S, et al. Drug-drug interaction studies of cardiovascular drugs involving p-glycoprotein, an efflux transporter, on the pharmacokinetics of edoxaban, an oral factor Xa inhibitor. Am J Cardiovasc Drugs. 2013;13(5):331-42.

9. Mendell J, Chen S, He L, Desai M, Parasrampuria DA. The effect of rifampin on the pharmacokinetics (PK) of edoxaban in healthy subjects. Clin Drug Investig. 2015;35(7):447-453.

10. Kubitza D, Becka M, Wensing G, Voith B, Zuehlsdorf M. Safety, pharmacodynamics, and pharmacokinetics of BAY 59-7939-an oral, direct Factor Xa inhibitor-after multiple dosing in healthy male subjects. Eur J Clin Pharmacol. 2005;61(12):873-80.

11. Stangier J, Rathgen K, Stahle H, Gansser D, Roth W. The pharmacokinetics, pharmacodynamics and tolerability of dabigatran etexilate, a new oral direct thrombin inhibitor, in healthy male subjects. Br J Clin Pharmacol. 2007;64(3):292-303.

12. Samama MM, Martinoli JL, LeFlem L, Guinet C, Plu-Bureau G, Depasse F, et al. Assessment of laboratory assays to measure rivaroxaban - an oral, direct factor Xa inhibitor. Thromb Haemost. 2010;103(4):815-25. 